\title{
Temperature monitoring in the subsurface during single lip deep hole drilling
}

\author{
Temperaturüberwachung in der Bohrungsrandzone beim Einlippentiefbohren
}

\section{Measuring of the thermomechanical load at different cutting parameters, including wear and simulative validation}

https://doi.org/10.1515/teme-2020-0055

Received July 20, 2020; accepted September 8, 2020

\begin{abstract}
The surface quality and the subsurface properties such as hardness, residual stresses and grain size of a drill hole are dependent on the cutting parameters of the single lip deep hole drilling process and therefore on the thermomechanical as-is state in the cutting zone and in the contact zone between the guide pads and the drill hole surface. In this contribution, the main objectives are the in-process measurement of the thermal as-is state in the subsurface of a drilling hole by means of thermocouples as well as the feed force and drilling torque evaluation. FE simulation results to verify the investigations and to predict the thermomechanical conditions in the cutting zone are presented as well. The work is part of an interdisciplinary research project in the framework of the priority program "Surface Conditioning in Machining Processes" (SPP 2086) of the German Research Foundation (DFG).

This contribution provides an overview of the effects of cutting parameters, cooling lubrication and including wear on the thermal conditions in the subsurface and mechanical loads during this machining process. At first, a test set up for the in-process temperature measurement will be presented with the execution as well as the analysis of the resulting temperature, feed force and drilling torque during drilling a 42CrMo4 steel. Furthermore, the results of process simulations and the validation of this applied FE approach with measured quantities are presented.
\end{abstract}

Keywords: Single lip deep hole drilling, monitoring, process temperature.

\footnotetext{
*Corresponding author: Robert Wegert, Institute for Machine Tools (IfW), Stuttgart, Germany, e-mail:

robert.wegert@ifw.uni-stuttgart.de

Vinzenz Guski, Siegfried Schmauder, Institute for Materials Testing, Materials Science and Strength of Materials (IMWF), Stuttgart, Germany

Hans-Christian Möhring, Institute for Machine Tools (IfW), Stuttgart, Germany
}

Zusammenfassung: Die Oberflächenqualität und die Randzoneneigenschaften wie Härte, Eigenspannungen und Korngröße einer Tiefbohrung sind von den Schnittparametern des Einlippentiefbohrprozesses abhängig und daher auch von dem thermomechanischen Ist-Zustand in der Zerspanzone und in der Kontaktzone zwischen den Führungsleisten und der Bohrungswand. Die Hauptpunkte dieses Beitrags sind die In-Prozess Messung des thermischen Ist-Zustandes in der Bohrungsrandzone mit Hilfe von Thermoelementen sowie die Auswertung von Vorschubkraft und Bohrmoment. FE-Simulationsergebnisse zur Verifizierung der Untersuchungen und zur Vorhersage der thermomechanischen Bedingungen in der Zertspanzone werden ebenfalls vorgestellt. Die Arbeit ist Teil eines interdisziplinären Forschungsprojekts im Rahmen des Schwerpunktprogramms „Oberflächenkonditionierung in der Zerspanung“ (SPP 2086) der Deutschen Forschungsgemeinschaft (DFG).

Dieser Beitrag gibt einen Überblick über die Auswirkungen von Schnittparametern, Kühlschmierung und Schneidenverschleiß auf die thermischen Bedingungen in der Randzone und auf die mechanischen Belastungen während dieses Bearbeitungsprozesses. Zunächst, wird der Versuchsaufbau für die In-Prozess Temperaturmessung vorgestellt, des Weiteren wird sowohl die Ausführung als auch die Analyse der resultierenden Temperaturen, Vorschubkräfte und der Bohrmomente beim Bohren eines 42CrMo4-Stahls präsentiert. Außerdem werden die Simulationsergebnisse und die Validierung des verwendeten FE-Ansatzes mit den experimentellen Ergebnissen vorgestellt.

Schlagwörter: Einlippentiefbohren, Prozessüberwachung, Prozesstemperatur. 

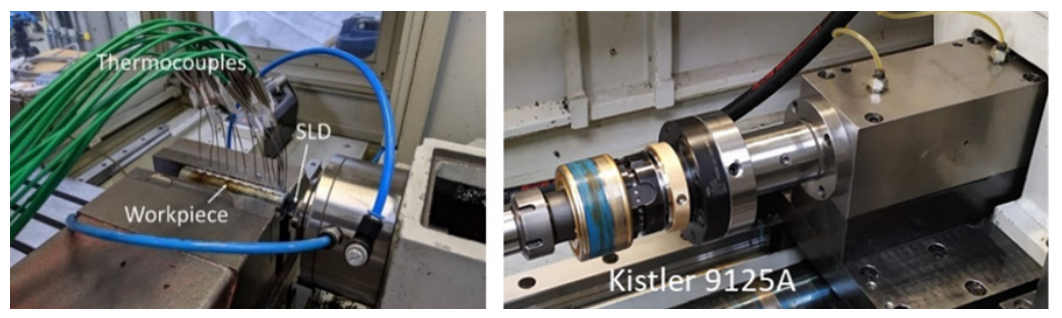

Figure 1: Experimental set up for temperature measurement with thermocouples on the subsurface of the drill hole.

\section{Temperature measurement along the drilling depth using thermocouples}

Single lip deep hole drilling is a machining process for producing deep holes with an $1 / \mathrm{d}$ ratio of up to 900 , with hole diameters between 0.5 and $80 \mathrm{~mm}$ [1]. This process fulfills very high quality requirements with respect to the achievable high surface quality and hole tolerances from IT8 to IT9 [2]. In addition to single lip deep hole drilling, there are further variants of deep hole drilling, such as BTA drilling or ejector drilling, which differ in the tool shape and the type of cooling lubricant supply. Characteristics of all deep hole drilling processes are the continuous chip removal as well as the better diameter tolerances, surface qualities, roundness and centerlines compared to spiral drilling.

The knowledge of the thermomechanical conditions in the cutting zone during the single lip deep hole drilling process is essential to achieve desired surface quality and subsurface properties in the drilling hole. The mechanical loads can be measured straightforward by a dynamometer, but the temperature monitoring is more challenging because of a difficult accessibility of the cutting zone during the drilling process. There are some methods to monitor the temperature, e.g. by means of installing thermocouples or resistance temperature sensors in the workpiece or the tool, or by using thermographic cameras or two-color pyrometers. The challenge is to measure the quantities as close as possible to the cutting zone. FE simulations can be carried out to investigate mechanisms in the cutting zone, to predict temperatures or to validate the measurement results. A method of determining the cutting zone temperature along the depth of the borehole using thermocouples is presented in this work. Cylindrical samples with a length of $100 \mathrm{~mm}$, and $25 \mathrm{~mm}$ outer diameter consisting of a quenched and tempered steel $42 \mathrm{CrMo} 4$ were used to carry out the experiments. The 16 thermocouples were positioned in such a way that the temperature location can be resolved higher at the beginning of the drilling process. The test setup can be seen in Fig. 1. Type K thermocouples are utilized with an outer diameter of $1 \mathrm{~mm}$. The measuring accuracy of the thermocouples is $\pm 2.5^{\circ} \mathrm{C}$. For data acquisition, the NI CompactRIO measuring system with NI 9213 module was used. The evaluation of the measuring signals was realized with the LabVIEW software. The 16 boreholes for the thermocouples are positioned perpendicular to the drilling direction with a distance of $0.2 \mathrm{~mm}$ from the drilling surface. A heat conducting paste was used to optimize the thermal contact conditions between the thermocouple and the workpiece. Special care was taken to ensure that the thermocouples are firmly seated so that they are fixed during the test. It was important that the thermocouples were not damaged during the process to record the temperature evolution in the whole drilling process, e.g. due to friction and forming processes between the guide pads and the drilling surface. In the first step the test was carried out three times without cooling lubrication. The machining parameters were kept constant throughout these three tests.

The feed force and the drilling torque were measured with a dynamometer of type $9125 \mathrm{~A}$ from the company KISTLER. The sampling rate per channel is $4 \mathrm{kHz}$ and the measuring range reaches up to a maximum of $3 \mathrm{kN}$ and $50 \mathrm{Nm}$. The used single lip driller (SLD) EB 800 was provided by the supplier Gühring KG. The SLD has a nominal diameter of $18 \mathrm{~mm}$, the exchangeable insert and the guide pads consisting of cemented carbides are TiAlN coated.

Figure 2 shows on the left the temperature evolutions at the 16 measuring points over the drilling depth in the third test under dry conditions. All three repetitions were made with one insert. Compared to the first test, the temperature level is increased by $150^{\circ} \mathrm{C}$, which is presumably due to the wear of the cutting edge. The wear progress should be accelerated by the lack of cooling lubricant [3]. The red markings in the diagram indicate the thermocouple positions along the drilling depth. The temperature at the beginning of the drilling process is slightly higher than the subsequent measured values, then the temperatures continue to rise until the temperatures decrease again from a drilling depth of approx. $65 \mathrm{~mm}$. The reason is that the part of heat energy, which is generated by the guide pads is not present in this area [1]. The maximum values of each individual measurement are offset to the 

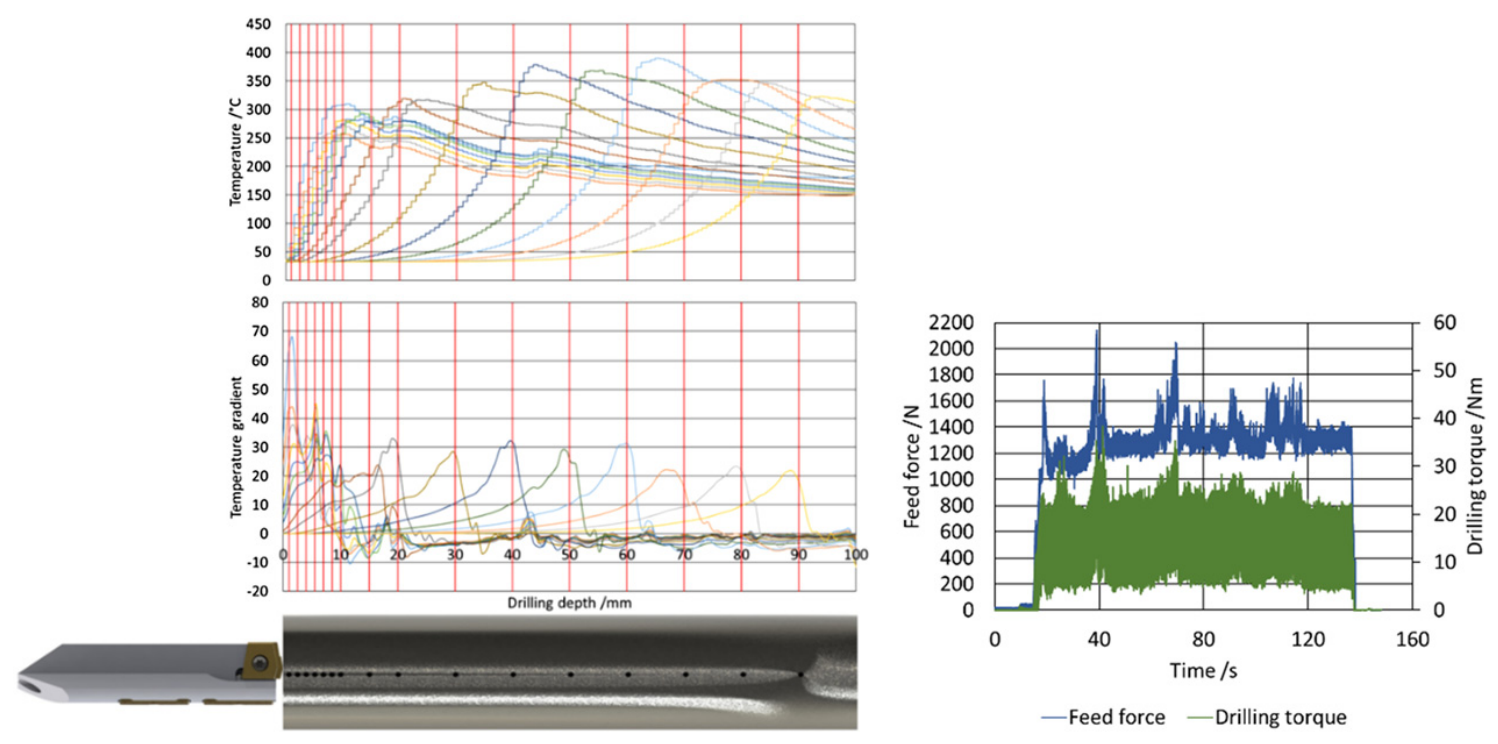

Figure 2: Left: Temperature and temperature gradient at the 16 positions along the drilling depth; right: the corresponding feed force and drilling torque; $v_{\mathrm{c}}=68 \mathrm{~m} / \mathrm{min} ; f=0.042 \mathrm{~mm}$; dry.

thermocouple positions. This is on the one hand due to the time offset caused by the heat flow and on the other hand, due to the additional heat energy input with a smaller gradient through the guide pads. The moment when the cutting edge passes a measuring point, the temperature rises with the highest gradient, as shown in Fig. 2. The gradient consideration is of importance for influencing the material properties in the borehole subsurface. The temperature level is below that of the thermographic measurements [4], because of the distance of $0.2 \mathrm{~mm}$ to the cutting zone. On the right side in Fig. 2 the corresponding feed forces and drilling torques are shown. The force peak at the beginning is typical for the single lip deep hole drilling process, the further peaks are caused by the chip accumulation, as the chip removal by the cooling lubricant is not given. The chip removal was only supported by compressed air.

\section{Temperature and mechanical load measurements with cutting parameter study and cooling lubricant influence}

Here, the previously described experiment has been carried out using deep hole drilling oil. A cooling lubricant pressure of $p=70$ bar and a flow rate of $\dot{V}=231 / \mathrm{min}$ was set. Furthermore, the cutting speed at constant feed was changed between three values and the feed was also varied at constant cutting speed. A new cutting insert was used for each cutting parameter set and repetition. Each parameter combination was repeated three times. For comparison, the same parameter studies were carried out with a cooling lubricant pressure of $p=30$ bar and a corresponding flow rate of $\dot{V}=15 \mathrm{l} / \mathrm{min}$, but without additional repetitions. The flow rate was monitored with a measuring device from KRACHT, type VC 0.4 F1 PS G-08 and the cooling lubricant pressure with a measuring device from ifm, type PN 9021.

Figure 3 on the left shows the temperature evolution at the 16 measuring points at a cutting speed $v_{\mathrm{c}}=65 \mathrm{~m} / \mathrm{min}$, a feed $f=0.05 \mathrm{~mm}$ and a coolant pressure of $p=70$ bar. In comparison to the dry drilled samples, the temperatures here are on average lower by a factor of five to eight. However, the shape of the temperature curve is very similar, initially the temperature rises sharply, followed by a drop, and slowly rises again. On the right side in Fig. 3 the corresponding mechanical loads are shown. Both the feed force and the drilling torque are on a lower level compared to dry machining. The arbitrary load peaks during drilling are not present.

On the left side in Fig. 4 the maximum temperatures at the respective sensor positions were compared at different cutting speeds, a constant feed and a coolant pressure of $p=70$ bar. Each value is an average of three measurements. The error bar represents a $95 \%$ confidence interval, which means that with an infinite number of repetitions, $95 \%$ of the measured values would lie within the shown range. Despite the wide spread, the hypothe- 

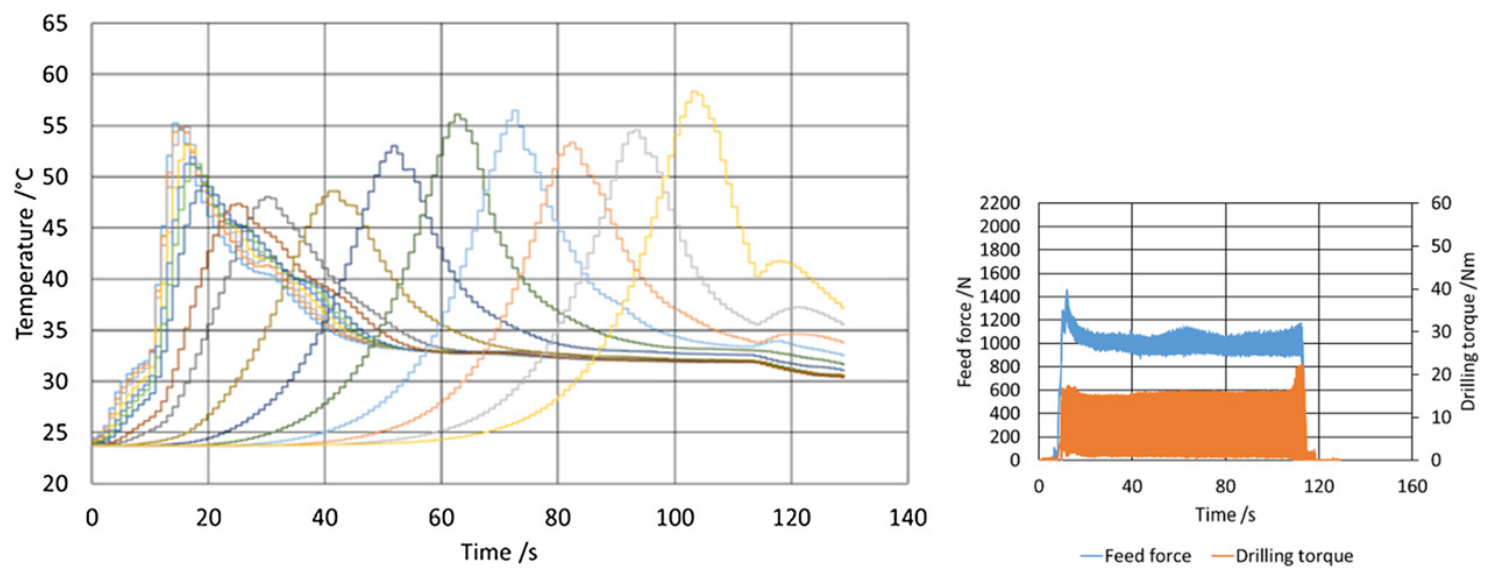

Figure 3: Left: Temperature at the 16 sensor positions; right: the corresponding feed force and drilling torque; $v_{\mathrm{c}}=65 \mathrm{~m} / \mathrm{min} ; f=0.05 \mathrm{~mm}$; lubrication: $\dot{V}=23 \mathrm{l} / \mathrm{min} ; p=70$ bar.

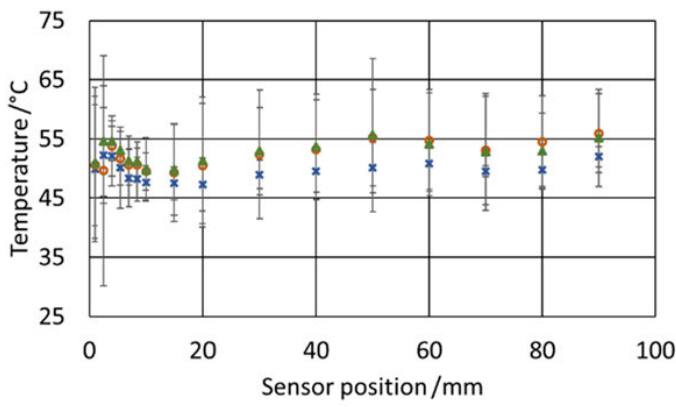

$\times f=0.05 \mathrm{~mm} ; v_{c}=50 \mathrm{~m} / \mathrm{min} \quad \circ f=0.05 \mathrm{~mm} ; v_{c}=65 \mathrm{~m} / \mathrm{min}$ $\Delta f=0.05 \mathrm{~mm} ; v_{c}=80 \mathrm{~m} / \mathrm{min}$

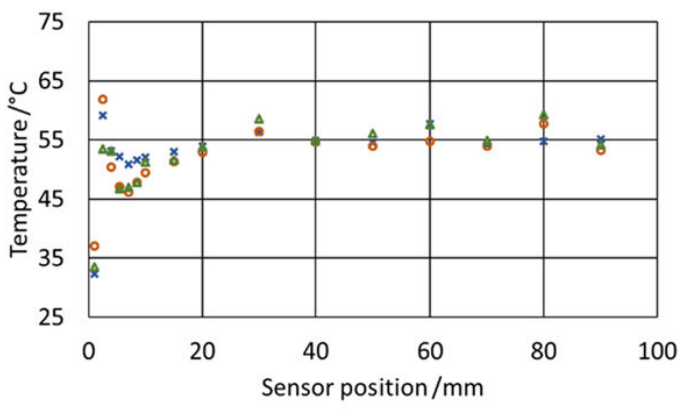

$\times f=0.05 \mathrm{~mm} ; v_{c}=50 \mathrm{~m} / \mathrm{min} \quad \circ f=0.05 \mathrm{~mm} ; v_{c}=65 \mathrm{~m} / \mathrm{min}$ $\Delta f=0.05 \mathrm{~mm} ; v_{c}=80 \mathrm{~m} / \mathrm{min}$

Figure 4: Maximum temperature along the drilling depth at different cutting speeds; left: $\dot{V} 23 \mathrm{l} / \mathrm{min} ; p=70$ bar; right: $\dot{V} 15 \mathrm{l} / \mathrm{min} ; p=30$ bar.

sis that the temperature also increases with increasing cutting speed can be confirmed. In this case, the tendency can be seen both during the beginning of drilling and in the further depth course, whereby the temperature values for $65 \mathrm{~m} / \mathrm{min}$ and $80 \mathrm{~m} / \mathrm{min}$ are very close to each other. On the right-hand side of Fig. 4 the results are shown for a lubrication with $p=30$ bar. Up to a depth of $20 \mathrm{~mm}$ the temperature spreads very strongly, in the so-called quasistatic range the temperatures are at $55-60^{\circ} \mathrm{C}$, which is $5^{\circ} \mathrm{C}$ higher than in the left diagram. The tendency towards higher temperatures with increasing cutting speeds is no longer clearly visible, which may be due to the fact that the values are not averaged from several repetitions. A similar behavior can also be observed when varying the feed at constant cutting speed (see Fig. 5). The temperatures in the right-hand diagram, i. e. at a lower coolant flow rate, are approx. $5^{\circ} \mathrm{C}$ higher. Besides, it can be seen, that especially at greater depths, the highest temperature values can be assigned to the maximum feed of $f=0.07 \mathrm{~mm}$.
Figure 6 summarizes the temperature and force behavior at different cutting speeds and cooling lubricant conditions. Here, the shown temperatures are averaged over 16 maximum values along the drill hole with three repetitions. As already mentioned, no repeat tests were carried out at a pressure of $p=30 \mathrm{bar}$. The feed forces are average values from the quasi-static range. At a cooling lubricant pressure of $p=70$ bar, the temperature increases with increasing cutting speed; no clear trend can be documented for the feed force. At a pressure of $p=30 \mathrm{bar}$, on the contrary, a decreasing tendency is clearly recognizable for the feed force.

In Fig. 7 the temperatures and forces have been evaluated using the same method to identify correlations with the feed rate. The feed force shows a clear increase with higher feed rate. There is also an increase in temperature, but there are clear differences depending on the cooling lubricant pressure. An FE simulation, which will be discussed in the following, provides very similar results 


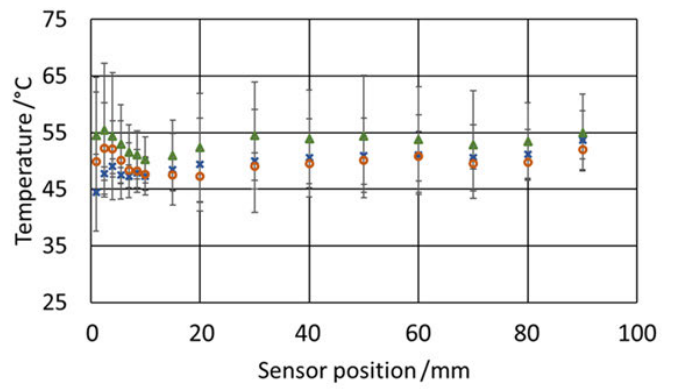

$\times f=0.03 \mathrm{~mm} ; v_{c}=50 \mathrm{~m} / \mathrm{min} \quad \circ f=0.05 \mathrm{~mm} ; v_{c}=50 \mathrm{~m} / \mathrm{min}$

$\Delta \mathrm{f}=0.07 \mathrm{~mm} ; v_{c}=50 \mathrm{~m} / \mathrm{min}$

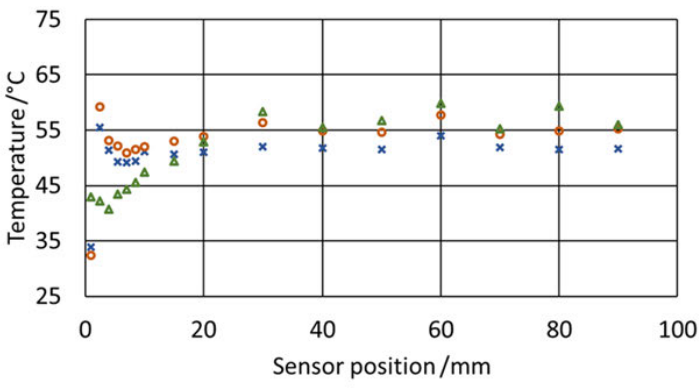

$\times f=0.03 \mathrm{~mm} ; v_{c}=50 \mathrm{~m} / \mathrm{min} \quad \circ f=0.05 \mathrm{~mm} ; v_{c}=50 \mathrm{~m} / \mathrm{min}$

$\Delta \mathrm{f}=0.07 \mathrm{~mm} ; v_{c}=50 \mathrm{~m} / \mathrm{min}$

Figure 5: Maximum temperature along the drilling depth at different feeds; left: $\dot{V}=23 \mathrm{l} / \mathrm{min} ; p=70$ bar; right: $\dot{V}=15 \mathrm{l} / \mathrm{min} ; p=30 \mathrm{bar}$.
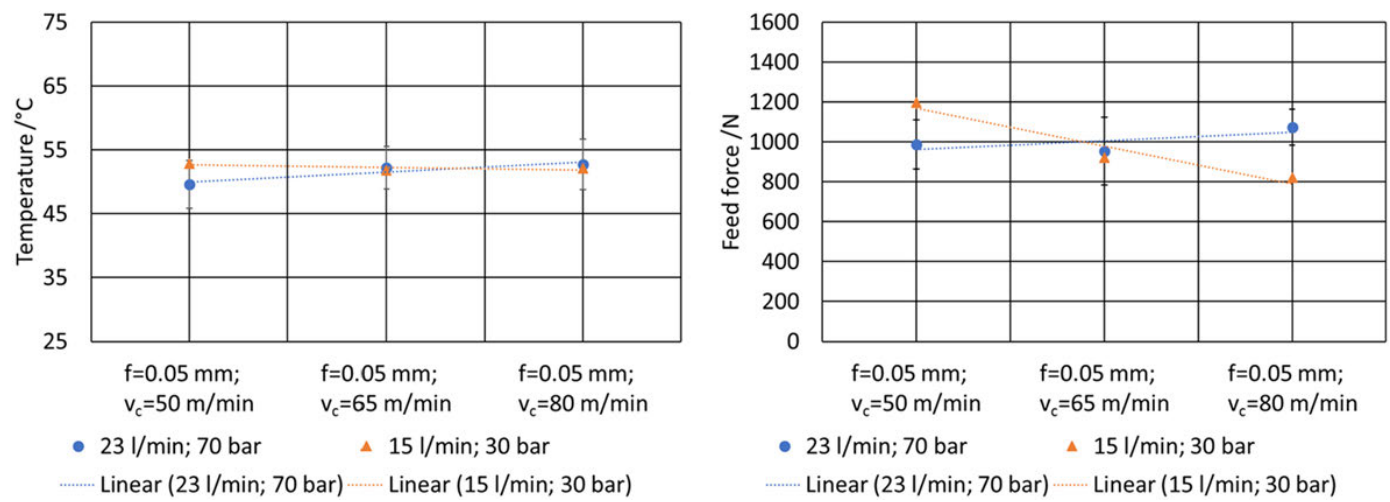

Figure 6: Left: mean temperature during SLD at different cutting speeds and cooling lubricant pressures; right: corresponding feed force.
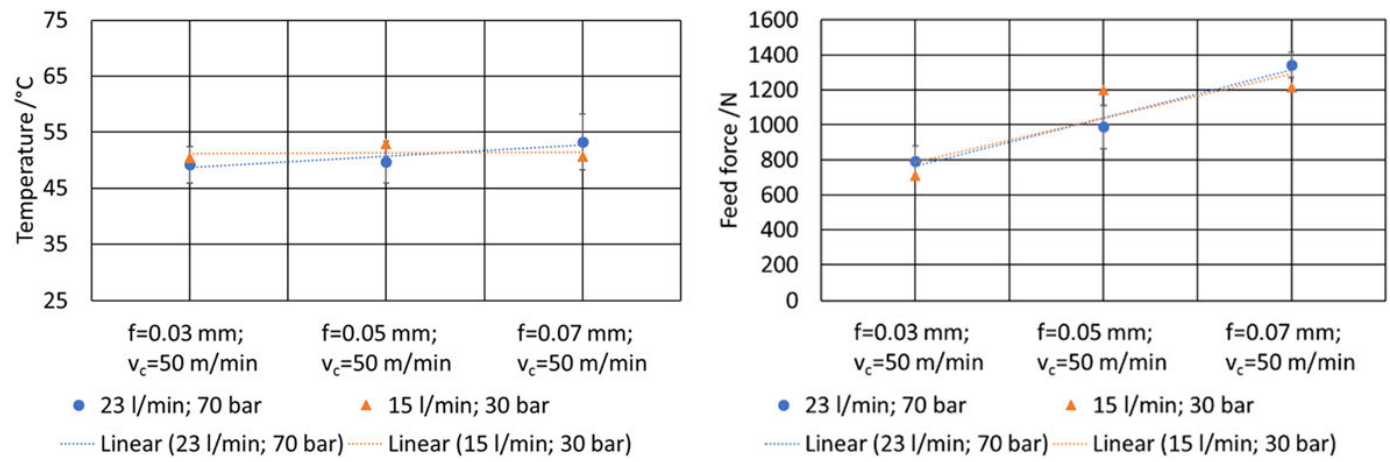

Figure 7: Left: mean temperature during SLD at different feeds and cooling lubricant pressures; right: corresponding feed force.
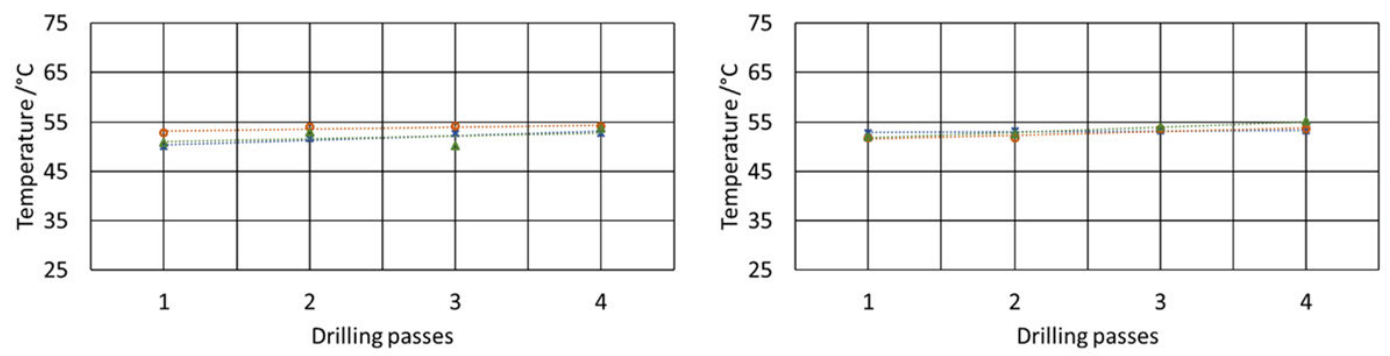

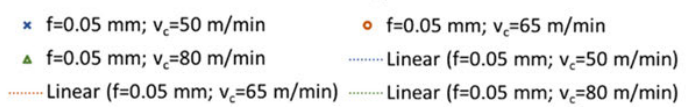

$\begin{array}{ll}\times f=0.05 \mathrm{~mm} ; v_{c}=50 \mathrm{~m} / \mathrm{min} & \circ f=0.05 \mathrm{~mm} ; v_{c}=65 \mathrm{~m} / \mathrm{min} \\ \Delta f=0.05 \mathrm{~mm} ; v_{c}=80 \mathrm{~m} / \mathrm{min} & \text { Linear }\left(f=0.05 \mathrm{~mm} ; v_{c}=50 \mathrm{~m} / \mathrm{min}\right) \\ \text { Linear }\left(f=0.05 \mathrm{~mm} ; v_{c}=65 \mathrm{~m} / \mathrm{min}\right) & \cdots . . .- \text { Linear }\left(f=0.05 \mathrm{~mm} ; v_{c}=80 \mathrm{~m} / \mathrm{min}\right)\end{array}$

Figure 8: Mean temperature during SLD at different wear levels and cutting speeds; left: $\dot{V}=23 \mathrm{l} / \mathrm{min} ; p=70$ bar; right: $\dot{V}=15 \mathrm{l} / \mathrm{min}$; $p=30$ bar. 

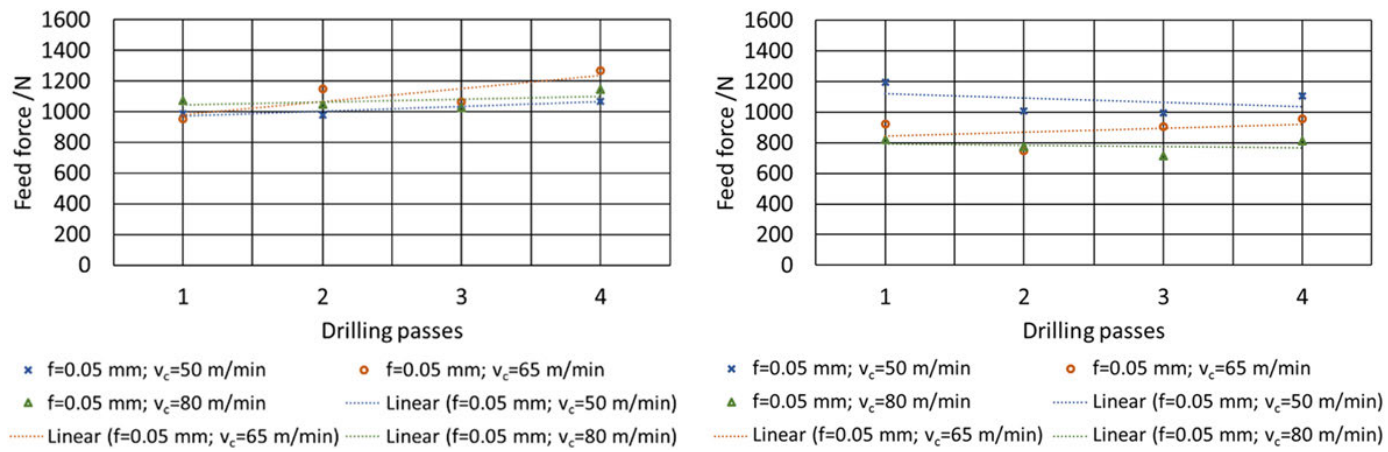

Figure 9: Mean feed force in quasi-static section during SLD at different wear levels and cutting speeds; left: $\dot{V}=23 \mathrm{l} / \mathrm{min} ; p=70 \mathrm{bar}$; right: $\dot{V}=15 \mathrm{l} / \mathrm{min} ; p=30$ bar.

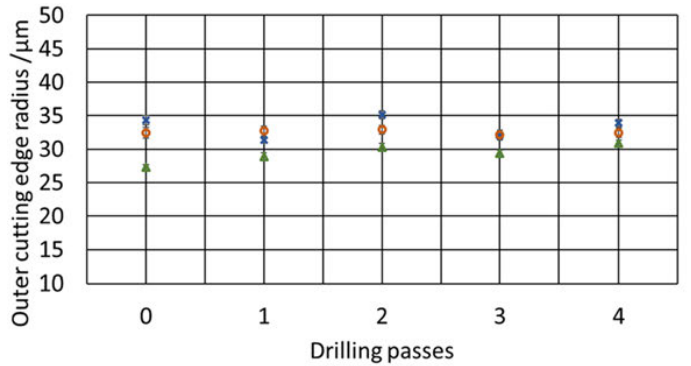

$\times f=0.05 \mathrm{~mm} ; v_{c}=50 \mathrm{~m} / \mathrm{min} \quad \circ f=0.05 \mathrm{~mm} ; v_{c}=65 \mathrm{~m} / \mathrm{min}$
$\Delta f=0.05 \mathrm{~mm} ; v_{c}=80 \mathrm{~m} / \mathrm{min}$

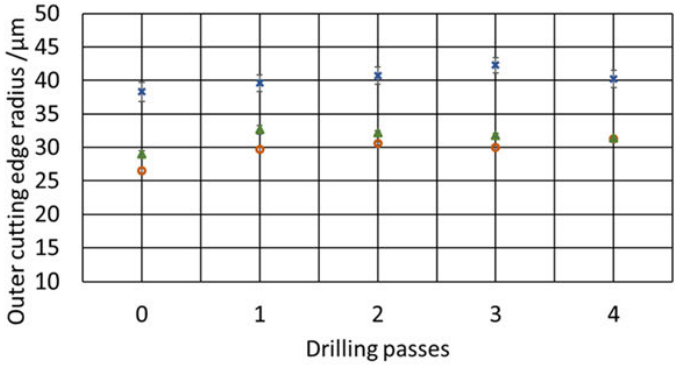

$\times f=0.05 \mathrm{~mm} ; v_{c}=50 \mathrm{~m} / \mathrm{min} \quad \circ f=0.05 \mathrm{~mm} ; v_{c}=65 \mathrm{~m} / \mathrm{min}$ $\Delta f=0.05 \mathrm{~mm} ; v_{c}=80 \mathrm{~m} / \mathrm{min}$

Figure 10: Outer cutting edge radius of the insert after several drilling passes and at different cutting speeds; left: $\dot{V}=23 \mathrm{l} / \mathrm{min} ; p=70 \mathrm{bar}$; right: $\dot{V}=15 \mathrm{l} / \mathrm{min} ; p=30$ bar.

(Fig. 17), but the dependencies of the thermomechanical parameters on the cutting parameters are clearer. This is due to the fact that a simulation is an idealized process and, in this case, no disturbing influences like chip removal or coolant conditions were considered.

\section{Effect of cutting edge wear on the temperature in the subsurface and mechanical loads}

\subsection{Effect of cutting edge wear at different cutting speeds}

The effect of cutting edge wear on the thermomechanical condition during single-lip deep hole drilling was also investigated. For this purpose, the previously described experiment was repeated four times with the same cutting insert for each parameter set. Besides the temperature in the subsurface, the feed force, the drilling torque and the cutting edge radius were measured. For the measurement of the cutting edge radii the optical system "InfiniteFocusG5" with the software module "EdgeMaster" of the company alicona was used. Fig. 8 shows the temperatures after four drilling passes of $100 \mathrm{~mm}$ long samples at different cutting speeds, on left at $p=70$ bar and on right at $p=30$ bar coolant pressure. As expected, both diagrams show an upward trend.

In Fig. 9, an increase in force can also be seen with an increasing number of drilling passes, although this is not clear at low coolant pressure. This can be caused by various disturbance variables that increase with a lower coolant flow rate, such as poorer chip removal. At $p=$ $30 \mathrm{bar}$, the feed force seems to drop after the first pass and then slowly increase again. In Fig. 10, the cutting edge radii of the outer cutting edge were plotted after each pass, as this area of the cutting edge is decisive for the subsurface and surface conditioning. Each point in these diagrams is an average of 50 values along the cutting edge. The error bar represents the $95 \%$ confidence interval. At 0 , the cutting edge radius of a new insert is plotted. The radii already show significant deviations when the inserts are new due to the manufacturing process. Therefore a direct 

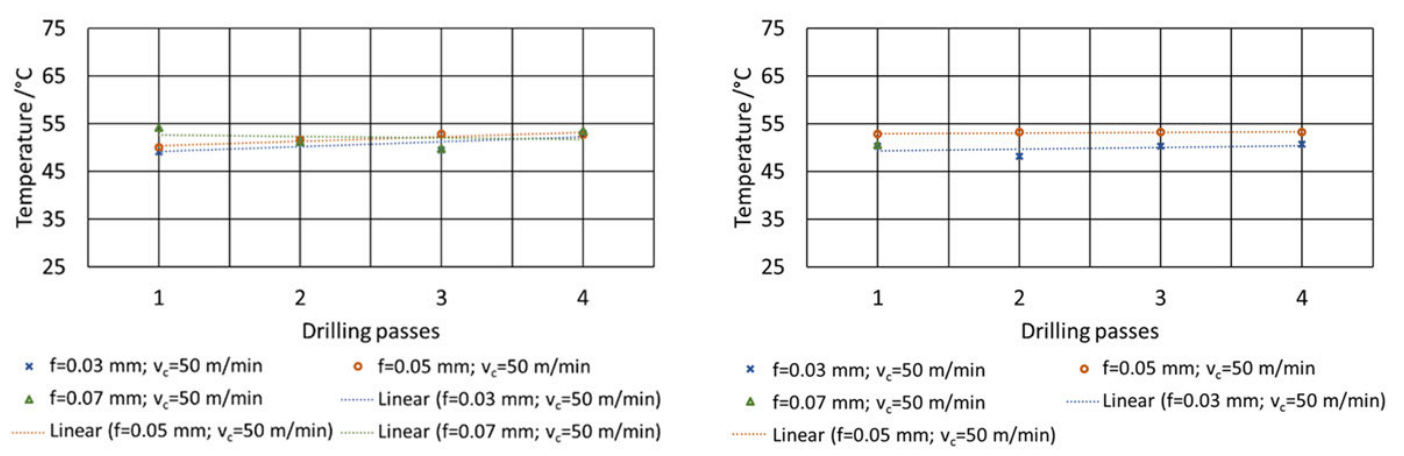

Figure 11: Mean temperature during SLD at different wear levels and feeds; left: $\dot{V}=23 \mathrm{l} / \mathrm{min} ; p=70$ bar; right: $\dot{V}=15 \mathrm{l} / \mathrm{min} ; p=30$ bar.
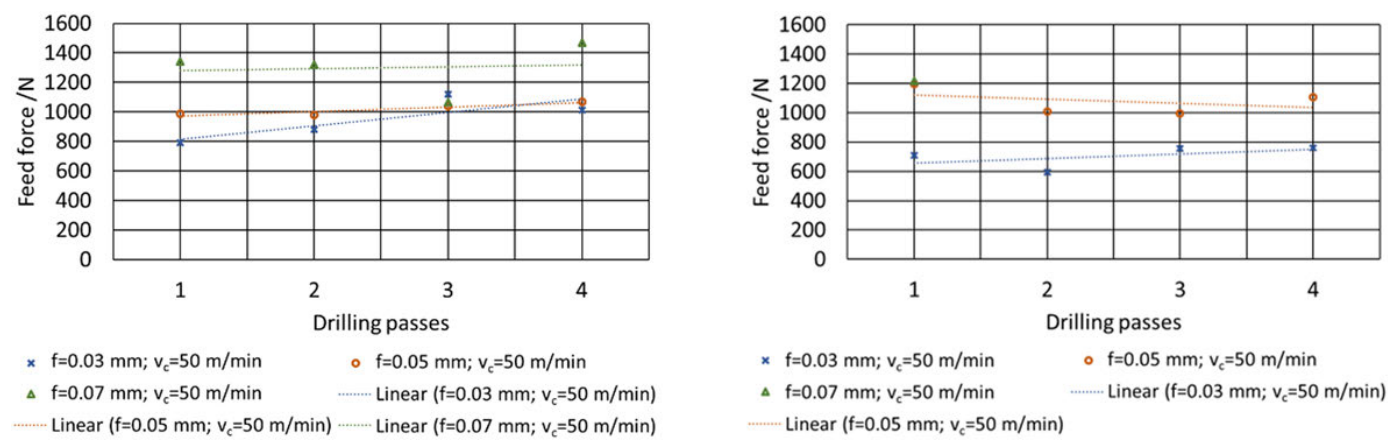

Figure 12: Mean feed force in quasi-static section during SLD at different wear levels and feeds; left: $\dot{V}=23 \mathrm{l} / \mathrm{min} ; p=70 \mathrm{bar} ;$ right: $\dot{V}=$ $15 \mathrm{l} / \mathrm{min} ; p=30 \mathrm{bar}$.

comparison of the absolute values between the different cutting speeds is less reasonable. However, the wear development with each pass for each parameter set and thus for each insert provides the expected tendency to increase the radius.

\subsection{Effect of cutting edge wear at different feeds}

In the same way, the influence of the feed on the mean maximum temperatures along the drill hole, as well as on the mean feed force in the quasi-static range and the cutting edge radii was investigated. In Fig. 11 the temperatures at $p=70$ bar on the left and at $p=30$ bar on the right are plotted. In the diagram on the left a clear increase in temperature with the number of passes can be seen, except for the parameter combination $f=0.07 \mathrm{~mm}$ and $v_{\mathrm{c}}=50 \mathrm{~m} / \mathrm{min}$. In this case, the values fluctuate strongly, which was also observed by the chattering in the process. With this parameter combination and $p=30$ bar cooling lubricant pressure, a breakout at the cutting edge corner was detected at the second pass and the test series was interrupted, see diagram on the right and Fig. 14. For the smaller feed rates, a slow increase in temperatures is also detectable at $p=30$ bar. The feed forces in Fig. 12 correlate with the temperatures in that way that the increase is more pronounced at $p=70$ bar than at $p=30$ bar. At $p=30$ bar, the difference between the series of measurements is also more pronounced. The force level of the problematic parameter set is $300 \mathrm{~N}$ higher than the comparative values.

The corresponding cutting edge radii, shown in Fig. 13, display an increase of the edge rounding predominantly. At $f=0.03 \mathrm{~mm}, v_{\mathrm{c}}=50 \mathrm{~m} / \mathrm{min}$ and $p=30$ bar lubricant pressure an opposite effect has occurred. The combination of parameters, which led to the break-out can be recognised by a very small radius after two passes, which can be explained by the sharp edges at the break-out point.

The light microscopic images of the cutting inserts after four drilling passes for qualitative wear investigation are shown in Fig. 14. The wear on the outer cutting edge or corner, see marking on the upper left hand side, can not only be quantitatively recorded but also visually identified.

For comparison, the radii of the central and inner cutting edges were plotted in Fig. 15, after four drilling samples no progressive wear can yet be detected. Also, the spreading in the initial condition is mentioned. 


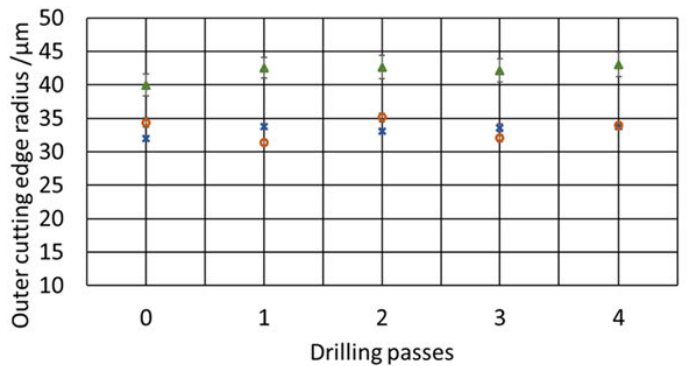

$\times f=0.03 \mathrm{~mm} ; v_{c}=50 \mathrm{~m} / \mathrm{min} \quad \circ f=0.05 \mathrm{~mm} ; v_{c}=50 \mathrm{~m} / \mathrm{min}$ $\Delta f=0.07 \mathrm{~mm} ; v_{c}=50 \mathrm{~m} / \mathrm{min}$

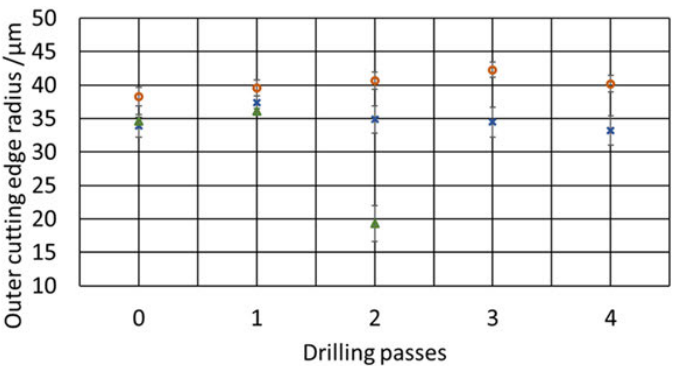

$\times f=0.03 \mathrm{~mm} ; v_{c}=50 \mathrm{~m} / \mathrm{min} \quad \circ f=0.05 \mathrm{~mm} ; v_{c}=50 \mathrm{~m} / \mathrm{min}$ $\Delta \mathrm{f}=0.07 \mathrm{~mm} ; v_{c}=50 \mathrm{~m} / \mathrm{min}$

Figure 13: Outer cutting edge radius of the insert after several drilling passes and at different feeds; left: $\dot{V}=23 \mathrm{l} / \mathrm{min} ; p=70$ bar; right: $\dot{V}=15 \mathrm{l} / \mathrm{min} ; p=30$ bar.
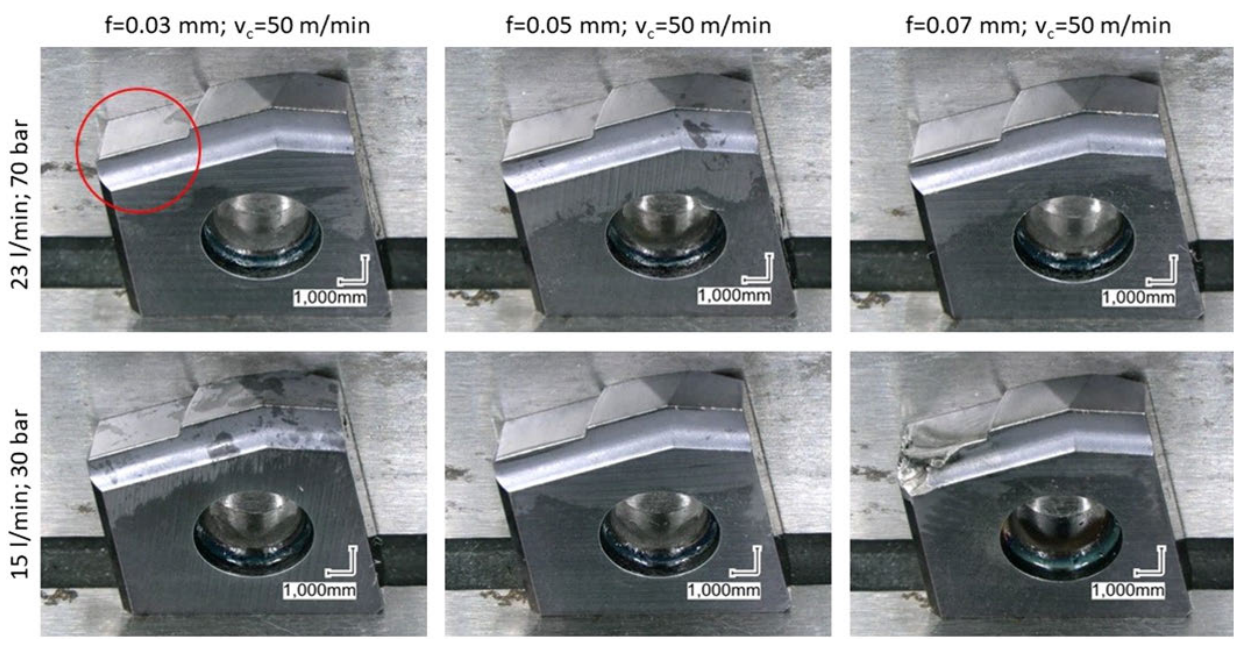

Figure 14: The inserts after 4 drilling passes at different feeds and cooling lubricant pressures.

\section{Validation of FEM simulation and experimental investigations}

For a deeper understanding of the mechanisms in the drilling process, FE simulations of this highly dynamic and unsteady-state process were conducted using the commercial solver ABAQUS with an explicit simulation scheme. Due to the huge computational costs when modelling the whole test set up, the FE model was reduced to the insert taken from CAD data of the company Gühring KG and a cylindrical workpiece. With this modelling setup, full 3D deep hole drilling process simulations were performed. Figure 16(a) shows a schematic representation of the FE modelling setup. The heat generation during the drilling process requires a coupled temperature displacement formulation of the solver, which allows the simulation of heat transfer as well as a stress analysis in parallel. In the framework of this work, the element elimination technique (EET) was chosen to represent the machining process. Those elements are removed from the FE model, which reach a previously defined critical measure according to the Johnson-Cook damage model.

Due to the high stiffness of the cemented carbide insert, it is defined as a rigid body. For modelling the material behavior of the workpiece during this highly dynamic process including large deformation and heat generation a strain rate as well as temperature dependent plasticity model, which is called Johnson-Cook (JC) constitutive model, was applied $[5,6]$. In order to move the insert according to the drilling process, a reference node was defined, which is linked to all of the nodes in the insert. Thus, on this reference node a lateral velocity along the driller axis and an angular velocity around this axis were applied. At the end of the simulation, this reference node delivered the reaction force of the insert to evaluate the simulation and to compare the results with the experiments. The initial temperature was set to room temperature. A gen- 

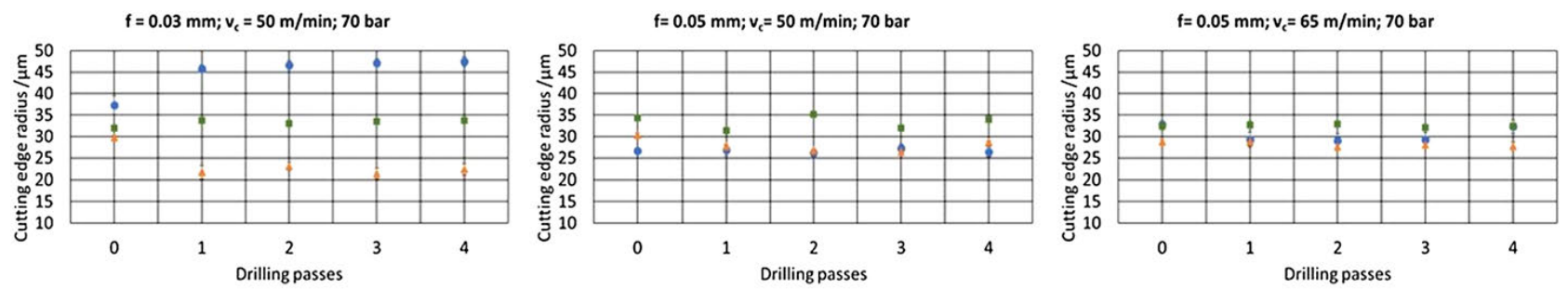

- inner cutting edge A center cutting edge = outer cutting edge

- inner cutting edge A center cutting edge = outer cutting edge

- inner cutting edge A center cutting edge = outer cutting edge

Figure 15: Cutting edge radii of the insert after several drilling passes and at different cutting parameters.

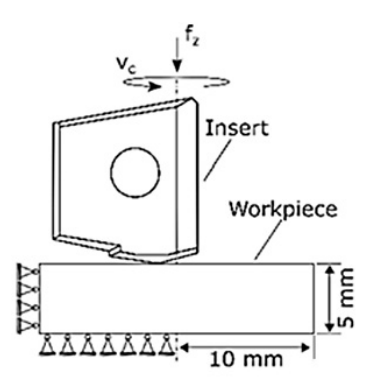

(a)

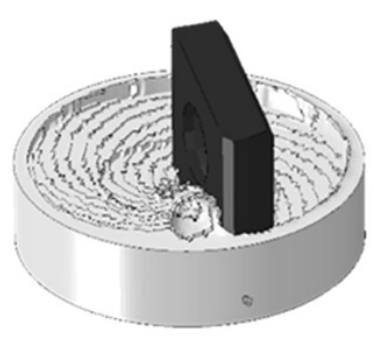

(b)

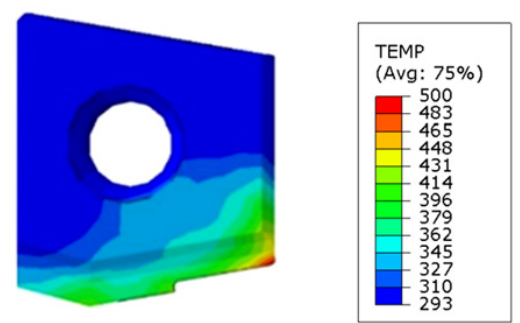

(c)

Figure 16: Schematic representation of the modelling set up (a), chip formation (b) and temperature distribution in the insert during the simulation.

eral contact was defined between the insert surface and the surface of the workpiece with a hard pressure overclosure correlation, which describes the interaction of the cutting insert and the workpiece in direction orthogonal to the surface. Further selected interaction properties are friction applying a Coulomb friction model with a friction coefficient $\mu$ of 0.5 as well as heat generation due to friction converting the deformation-induced energy into heat [7]. Besides, boundary conditions were applied to constrain the movement of the workpiece. In this simulation, the degrees of freedom at the bottom surface as well as the lateral surface of the cylindrical workpiece are restricted (see Fig. 16(a)). Finally, this established FE model is able to reproduce chip formation during the drilling process nicely (see Fig.16 (b)).

In the presented numerical study, a sensitivity analysis with different cutting speeds $v_{\mathrm{c}}$ and feeds $\mathrm{f}$ was carried out.

Due to the huge computational effort of 3D process simulations using experimental process parameters, the parameters in the simulations are higher compared to the experimental ones. To reduce this parameter gap, the lowest feed in the simulations was defined as $0.08 \mathrm{~mm}$, which is slightly higher than the highest feed in the experiment $(0.07 \mathrm{~mm})$. The simulations were performed under the as- sumption of dry conditions. Considering the fluidic lubricant was not part of this study and increases the numerical effort dramatically. However, the numerical results still can be used to study the mechanisms as well as the general correlation between the process parameters and the resulting quantities feeding force and temperature. In order to validate the simulation, the measured quantities feeding force and temperature were compared with the numerical results. The temperature is captured at the position of maximum temperature on the cutting insert at the end of the simulation where a steady-state is reached (see Fig. 16(c)). Besides, the resulting feeding force was examined with respect to the process parameter feed and cutting speed. The results are summarized in Fig. 17.

Maximum temperatures around $400{ }^{\circ} \mathrm{C}$ to $700{ }^{\circ} \mathrm{C}$ with increasing feed were obtained. This temperature range is comparable to the experimental results of drilling under dry conditions, which are presented in [4]. The resulting feeding force for a feed of $0.08 \mathrm{~mm}$ (Fig. 17 (a)) is with $2.4 \mathrm{kN}$ almost the double compared to the experimental value of $1.4 \mathrm{kN}$ in Fig. 7 (right) for a feed of $0.07 \mathrm{~mm}$ with lubricant and a lower cutting speed, respectively. With these results, the effect of the cooling lubricant on the drilling process can be extracted. Generally, the sensitivity study on the feed indicates, that the feeding force is 


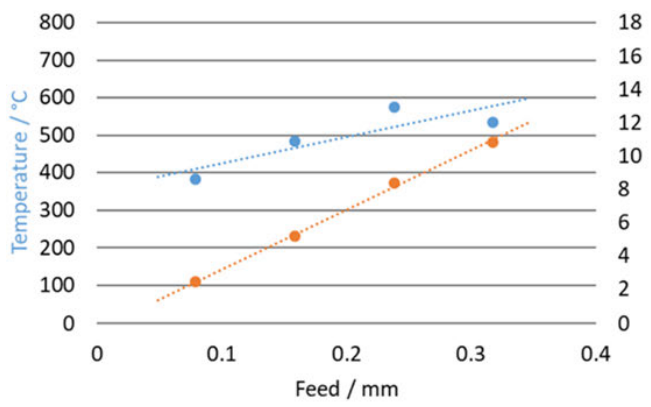

(a)

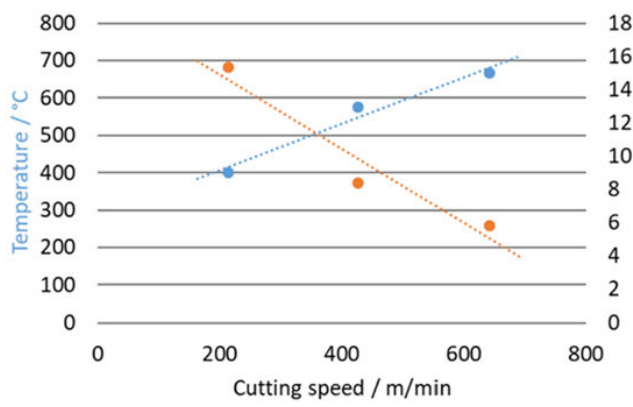

(b)

Figure 17: Numerical results of the drilling simulation with varying feed with a constant cutting speed of $427.51 \mathrm{~m} / \mathrm{min}$ (a) and cutting speed with feeds of $0.48 \mathrm{~mm}, 0.24 \mathrm{~mm}$ and $0.16 \mathrm{~mm}$ (b) under dry conditions.

highly dependent on this quantity: The lower the feed, the lower the resulting feed force. The trend of the feeding force with the experimental feeds of $0.03 \mathrm{~mm}, 0.05 \mathrm{~mm}$ and $0.07 \mathrm{~mm}$ in Fig. 6 and Fig. 7, is extended by the numerical results, which indicates a good representation of the dominant mechanisms in the drilling process. A reversed influence of the cutting speed on the feeding force is shown in Fig. 17(b), which means at the end a decreased feed. This correlation agrees well with the trend indicated through the experimental results in Fig. 9 and Fig. 10. Nevertheless, further numerical investigations are needed to overcome the drawback of the higher process parameters and to deliver more reliable results.

\section{Conclusions}

In this paper, investigations were presented focusing on the thermomechanical state during single lip hole drilling with respect to the drilling depth. Different coolant strategies were applied, 30 and 70 bar coolant pressure as well as dry cutting. In addition, the wear of the cutting edges was measured. Very significant differences were found between drilling without coolant and conventional drilling with lubrication. After three dry drilling passes with one cutting insert, the average temperature in the subsurface increased by approx. $150^{\circ} \mathrm{C}$, using deep drilling oil the temperature increased by max. $2^{\circ} \mathrm{C}$. Only slight differences in terms of temperature and feed force were found between 30 and 70 bar coolant pressures. As expected, microscopic investigations on the insert confirmed that the outer edge is the location with the highest wear. With critically selected cutting parameters, a lower coolant pressure can lead to cutting edge outbreaks. In addition, it has been shown that the initial conditions and the dimensional accuracy of the cutting edges have a significant effect on the experimental results. Large temperature deviation and a force peak were observed at the beginning of the drilling process. The higher mechanical load can have several reasons. At the beginning there are different contact conditions between insert and workpiece, which change continuously. This results in a different stress distribution in the driller and other reaction forces. After a certain drilling depth, the contact conditions are almost constant. The monitoring of the thermomechanical condition is an essential component for the adjustment of the subsurface properties in the drilling hole.

Acknowledgment: The authors thank the DFG for this funding and intensive technical support. Also, the authors acknowledge the company Gühring KG for providing technical support.

Funding: The scientific work has been supported by the DFG within the research priority program SPP 2086 under Grant Nos. MO 2091/6-1 and SCHM 746/211-1.

\section{References}

1. D. Biermann, F. Bleicher, U. Heisel, F. Klocke, H. C. Möhring, and A. Shih, "Deep hole drilling," CIRP Annals, vol. 67, no. 2, pp. 673-694, 2018.

2. VDI 3210 Blatt 1, Tiefbohrverfahren, 2006.

3. M. Cuesta, P. Aristimuño, A. Garay, and P. Arrazola, “Heat transferred to the workpiece based on temperature measurements by IR technique in dry and lubricated drilling of Inconel 718," Applied Thermal Engineering, vol. 104, pp. 309-318, 2016.

4. R. Wegert, V. Guski, S. Schmauder, and H.-C. Möhring, "Effects on surface and peripheral zone during single lip deep hole drilling," Procedia CIRP, 5th CIRP Conference on Surface Integrity, pp.113-118, 2020.

5. O. Pantalé, J. L. Bacaria, O. Dalverny, R. Rakotomalala, and S. Caperaa, "2D and 3D numerical models of metal cutting with 
damage effects," Computer Methods in Applied Mechanics and Engineering, vol.193, no. 39-41, pp. 4383-4399, 2004.

6. G. R. Johnson and W. H. Cook, "Fracture characteristics of three metals subjected to various strains, strain rates, temperatures and pressures," Engineering Fracture Mechanics, vol 21, no.1, pp. 31-48, 1985.

7. S. F. Miller and A. J. Shih, "Thermo-mechanical finite element modeling of the friction drilling process," Journal of Manufacturing Science and Engineering, vol 129, pp.531-538, 2007.

\section{Bionotes}

\section{Robert Wegert}

Institute for Machine Tools (IfW), Stuttgart, Germany

robert.wegert@ifw.uni-stuttgart.de

Robert Wegert: since July 2018 Research Assistant - Metal Cutting, Institute for Machine Tools, University of Stuttgart; since March 2018

Master of Science (Mechanical Engineering/Materials and Production Engineering), University of Stuttgart.

\section{Vinzenz Guski}

Institute for Materials Testing, Materials Science and Strength of

Materials (IMWF), Stuttgart, Germany

vinzenz.guski@imwf.uni-stuttgart.de

Vinzenz Guski: since May 2019 Head of Continuums mechanic group - Institute for Materials Testing, Materials Science and Strength of Materials (IMWF), University of Stuttgart; since April 2012 Research Assistant - Institute for Materials Testing, Materials Science and Strength of Materials (IMWF), University of Stuttgart; 2006-2012 Study of material science at the University of Stuttgart; Dipl.-Ing.
Univ.-Prof. Dr.-Ing. Hans-Christian Möhring Institute for Machine Tools (IfW), Stuttgart, Germany hans-christian.moehring@ifw.uni-stuttgart.de

Hans-Christian Möhring: since 2019 Dean of the Faculty of Design, Production and Automotive Engineering; since 2017 Chairman of the examination board for technical education, University of Stuttgart; since 2017 University Professorship for Machine Tools, University of Stuttgart, Director of the Institute for Machine Tools (IfW), University of Stuttgart; 2012-2017 University professor at the Otto-von-Guericke University Magdeburg, head of the "Production Equipment" department; 2005-2012 Chief Engineer at the IFW of the Leibniz University Hannover; 1993-1999 Study of mechanical engineering at the Leibniz University of Hannover; Dipl.-Ing.

Prof. Dr. rer. nat. Dr. h. c. Siegfried Schmauder

Institute for Materials Testing, Materials Science and Strength of Materials (IMWF), Stuttgart, Germany

siegfried.schmauder@imwf.uni-stuttgart.de

Siegfried Schmauder: Since 1994 W3-Professor for Strength of Materials and Materials Science, Institute for Materials Testing, Materials Science and Strength of Materials, University of Stuttgart, Germany; 1991-1994 Leader, Structural Mechanics Group, at the Max-PlanckInstitute for Metals Research, Stuttgart, Germany; 1990-1991 Visiting Scientist at the University of California (USA), DFG-Research Fellowship; 1989-1990 Visiting Scientist at the University of Tokyo (Japan), JSPS-Research Fellowship; 1988-1989 Representative Leader, Electron Microscopy Group at the Max-Planck-Institute for Metals Research, Stuttgart, Germany; 1982-1988 Scientific Assistant at the Max-Planck-Institute for Metals Research, Stuttgart, Germany; 19751981 Study of Mathematics, University of Stuttgart; Diploma (subsidiary subject: Informatics). 